\title{
COLECCIONES EDITORIALES DE LA DÉCADA DE 1960 Y PRINCIPIOS DE 1970 EN ARGENTINA. LAS COLECCIONES SOBRE COMUNICACIÓN
}


COLECCIONES EDITORIALES DE LA DÉCADA DE 1960 Y PRINCIPIOS DE 1970 EN ARGENTINA. LAS COLECCIONES SOBRE COMUNICACIÓN

Resúmen:

Nos proponemos relevar y analizar el fenómeno de las emergencias de las colecciones editoriales a finales de la década de 1960 y principios de la de 1970. Momento en el que emerge con fuerza en Argentina el interés por la comunicación y sus problemáticas en un contexto fuertemente atravesado por la política. Indagaremos en las características de la colección Comunicación de masa de la Editorial Siglo XXI y su contexto de emergencia.

Palabras Clave: Comunicación; Editoriales; Colecciones; Década de 1960; Década de 1970

COLEÇÕES EDITORIAIS DA DÉCADA DE 1960 E INÍCIO DE 1970 NA ARGENTINA. AS COLEÇÕES SOBRE COMUNICAÇÃO

Resumo:

Temos a intenção de levantar e analisar o fenômeno da emergência coleções editoriais no final dos anos 1960 e início dos anos 1970. Tempo, quando a Argentina surge fortemente no interesse da comunicação e seus problemas em um contexto fortemente atravessado pela política. Iremos investigar as características da coleção comunicação de massa da Editorial Siglo XXI e seu contexto de emergência.

Palavras chave: Comunicação; Editoriais; Coleções; Década de 1960; Década de 1970

EDITORIAL COLLECTIONS OF 1960'S AND EARLY 1970'S IN ARGENTINE. THE COLLECTIONS ABOUT COMMUNICATION

\begin{abstract}
:
We intend to raise and analyze the phenomenon of emergence collections editorials in the late 1960 s and early 1970s. Period when Argentina emerges strongly in the interest of communication and its problems in a context heavily traversed by the policy. We will investigate the characteristics of mass communication collection of Editorial Siglo XXI and its emergency context.
\end{abstract}

Keywords: Communication; Editorials; Collections; 1960s; 1970 s 


\section{INTRODUCCIÓN}

El proyecto de investigación dentro del cual se inscribe esta ponencia lleva como título El orden de lo diverso. Un estudio sobre las colecciones argentinas en los años sesenta. Pertenece a la Universidad Nacional de Quilmes y está dirigido por la Dra. Margarita Pierini.

La propuesta está vinculada a un proyecto global de la investigadora Christine Rivalan-Guégo, de la Universidad de Rennes II, que se propone analizar la progresiva emergencia de las colecciones en la historia editorial de diferentes áreas geográficas del mundo hispánico en relación con el contexto histórico-cultural en el que surgen.

Los estudios sobre la actividad editorial son objeto de especial interés desde hace varias décadas de parte de investigadores de diversas disciplinas, que desde distintos abordajes -literarios, históricos, bibliotecológicos, comunicacionales, de estudios culturales, estudios sobre la recepción, entre otros-, pusieron en foco la complejidad de un fenómeno inherente a la cultura de la letra escrita, en sus múltiples manifestaciones, formatos y destinatarios.

Estas investigaciones tienen en nuestro país una rica tradición, que va desde los testimonios de los pioneros de la edición argentina -que pueden datarse desde finales del siglo XIX- hasta los trabajos que han abordado en forma sistemática la producción editorial de los últimos 150 años.

Quedan, sin embargo, en ese campo de estudios, muchas áreas por completar, profundizar, incluso por descubrir, y sobre todo, por destacar el interés que ofrecen a los que se preocupan por esta faceta del gran conjunto que es la relación entre autor-editor-lector, como fenómeno que se desarrolla en el tiempo atravesado por las transformaciones de una sociedad a la que refleja y con la cual dialoga.

El estudio de las colecciones que, a partir de mediados del siglo XIX, se definen y organizan dentro de las grandes editoriales europeas como un elemento ordenador que reúne temáticas, géneros y autores afines -atentas a la conformación de un público cada vez más amplio y por ende más diversificado-, se constituye entonces como un nuevo objeto de investigación.

La "puesta en serie", la inclusión en una colección implica un ordenamiento, una clasificación, regida por un criterio que proviene inicialmente del editor y que, una vez instalado el sistema, podrá asignarse a una nueva figura, como es el director de colección. Incorporar una obra dentro de una colección va a constituir una estrategia, que en algunos casos otorgará una nueva identidad al texto, al destinarlo a un público a veces impensado por el autor.

Nuestra propuesta se plantea relevar y analizar el fenómeno de las colecciones que surgieron en nuestro país en una etapa cuya particular capacidad de renovación, creatividad e influencia sobre la sociedad -la de su tiempo y la contemporánea a nosotros- ha sido objeto de una valiosa y exhaustiva bibliografía: los años sesenta. 
Los ejemplos paradigmáticos son la editorial de la Universidad de Buenos Aires, EUDEBA y el Centro Editor de América Latina. Pero a ellos se suman las numerosas editoriales que, con mayor o menor perduración, mayor o menor difusión, apuntaron a cubrir las demandas de un público motivado por intereses plurales, abiertos y cuyos volúmenes recuperamos con una nueva mirada al recorrer nuestras bibliotecas personales, librerías de viejo o repertorios institucionales.

Como antecedente en la línea de investigación que aquí presentamos, nos remitimos al proyecto I+D Más libros para más lectores. Editoriales argentinas de difusión masiva (1900-1940), desarrollado entre los años 2004 y 2007 en la Universidad nacional de Quilmes bajo la misma dirección que el actual proyecto. En este caso se conformó un equipo integrado por cuatro investigadores provenientes de diferentes disciplinas, del ámbito de las Letras, de la Edición, de Bibliotecología y de la Comunicación social.

El campo editorial del período seleccionado se caracteriza como es sabido por su amplitud y diversidad. Por eso, para la primera etapa del proyecto se han demarcado algunos ejes de análisis -acordes con las propuestas y los intereses de los integrantes del equipo- , sobre aspectos que consideramos no han sido aun suficientemente explorados: el trazado de una cartografía de los espacios editoriales establecidos en el período para ubicar sobre ella las nuevas propuestas que aportan las colecciones de reciente creación; las Colecciones argentinas de Literatura Infantil Juvenil; Nuevas letras argentinas: análisis de las propuestas editoriales misceláneas que integran la literatura argentina; Libros y colecciones de Ciencias Sociales, el caso de la Editorial La Rosa Blindada (1964-1974) y las Colecciones sobre Comunicación aparecidas durante el período.

El estudio de las colecciones que aquí proponemos busca ofrecer una nueva perspectiva para indagar en la historia cultural de nuestro tiempo.

\section{EL PERÍODO SELECCIONADO}

En esta primera etapa -y con el fin de ir conformado una cartografía de colecciones- seleccionamos como marco temporal el período de los años sesenta, una época signada por el cambio y la renovación de horizontes y modelos, en la cual la ruptura de las tradiciones culturales se hace evidente en algunas de las propuestas editoriales que definirían el perfil del debate intelectual de esos años.

Acorde con esa renovación que se manifiesta en múltiples registros, el surgimiento de numerosas colecciones en editoriales tanto tradicionales como de reciente creación da cuenta de nuevos intereses por parte de un público lector, de un oído atento a las transformaciones del campo intelectual, por parte de los editores, de los préstamos e intercambios con modelos extranjeros, de 
nuevas formas de lectura, en definitiva, de un programa de ideas que apunta a construir un ciudadano ya no sólo ilustrado sino comprometido con su tiempo y su sociedad.

Elegimos este período por que constituyó una etapa de florecimiento editorial sin antecedentes en el país, tanto por el número de editoriales vigentes -las tradicionales como Losada, Peuser, Emecé, Siglo Veinte, Sur, Peña Lillo, entre muchas otras, junto con las de reciente creación, como Jorge Álvarez, De La Flor, Carlos Pérez, Siglo XXI, Galerna, CEAL- como por los tirajes alcanzados y el número de reediciones que alcanzan infinidad de títulos. A la vez, elegimos este periodo entendiendo que este boom editorial constituye una clara representación de la pluralidad de intereses que mueven a un amplio sector de lectores motivados por el contexto histórico y político de la época, unido, como dato no menor, a una etapa de prosperidad económica sustentada en una creciente equidad en la distribución del ingreso.

Proponemos como cierre del periodo a estudiar -dentro de la inevitable arbitrariedad para la delimitación de fechas- el inicio del Proceso Cívico-Militar, dado que en el campo editorial el corte producido por el Golpe de 1976 tiene consecuencias particularmente decisivas para los proyectos en pleno desarrollo: desde la desaparición de editores, escritores e integrantes de los equipos editoriales (Cf. Inverizzzi-Gociol 2003), o su exilio, hasta la destrucción de millones de ejemplares de CEAL y Eudeba (ibid.), y el cierre de editoriales y librerías, en cuyo proceso las profundas crisis económicas no fueron un factor menor. $\mathrm{Y}$, por último, la vigilancia de los censores que, más allá del secuestro de títulos, instaló por años el disciplinamiento, la autocensura, a través del cese de proyectos en marcha o de su reconversión hacia géneros, temáticas e ideas prudentemente esterilizados. ${ }^{1}$

\section{LOS ESTUDIOS DE COMUNICACIÓN}

A finales de la década de 1960 y principios de la de 1970 emerge con fuerza el interés por la comunicación y sus problemáticas en un contexto fuertemente atravesado por la política. La investigación acerca de la comunicación social, en Argentina, se desarrolló fundamentalmente a partir de esos años.

Si bien podría decirse que con el auge de las facultades de Comunicación en Argentina, que se dio recién después del regreso de la democracia, en 1983, se consolida mayormente un público académico para el campo de la comunicación y a partir de allí toman forma colecciones representativas del área, el período que nos convoca en esta investigación presenta antecedentes que fueron conformando el campo profesional y que si bien no muestra en todos los casos colecciones específicas de comunicación entre aproximadamente 1960 y 1Estos primeros apartados de la ponencia reproducen parte de la propuesta presentada y aprobada del proyecto I+D El orden de lo diverso. Un estudio sobre las colecciones argentinas en los años sesenta, Universidad Nacional de Quilmes. 
1970, sí podemos ver obras independientes sobre la temática o ediciones que forman parte de colecciones de otras disciplinas (Ciencias sociales, Lingüística, Psicología, Educación, entre otras).

De esta manera se va armando un mapa previo de colecciones, que en principio, podríamos decir se fue formando a la par de la consolidación del campo profesional. A partir de finales de 1960 y principios de 1970 comienzan a aparecer las primeras colecciones que específicamente llevan como nombre la referencia al campo de estudio (Vg. Comunicación de masa, Serie comunicaciones). Nos interesa indagar en las características de esa emergencia, de modo que nos permita a partir del objeto colecciones, comprender el desarrollo del campo editorial específico de la comunicación.

Las polémicas de la época en relación con los estudios de comunicación nos ofrecen algunas pistas para rastrear ediciones que se transformaron en marcos de referencia y que de a poco fueron conformando un corpus de publicaciones que, como dijimos, podemos considerar antecedentes válidos de futuras colecciones.

Algunos datos de referencia nos muestran ejes por donde se desarrollaban los estudios de comunicación en Latinoamérica y en Argentina.

En 1959 - a partir de la UNESCO, la OEA y el gobierno de Ecuador-surge con sede en Quito el Centro Internacional de Estudios Superiores de Comunicación para América Latina (CIESPAL). El CIESPAL generó una influencia importante en todo el continente.

La investigación acerca de la comunicación social, en Argentina, se desarrolló fundamentalmente a partir de esos años y en general de la mano de investigadores reconocidos como Néstor García Canclini, Hector Schmucler y Eliseo Verón, entre otros.

La investigación crítica se ve influenciada, a su vez, por la educación popular de Paulo Freire en Brasil, que deja al descubierto la verticalidad comunicacional y la ausencia de diálogo. En ese sentido, en 1973 publicó su primer libro Mario Kaplún: La comunicación de masas en América Latina.

La publicación del libro Para leer al Pato Donald, de Armand Mattelart y Ariel Dorfman dejó su marca también en los nacientes estudios en comunicación en América latina.

Por esta misma época se destacaron dos revistas especializadas, que en su momento generaron fuertes debates. Por un lado, Lenguajes: Revista de Linguística y Semiología, que fue publicada por la Asociación Argentina de Semiótica (con trabajos de Oscar Steimberg, Oscar Traversa y Eliseo Verón, que además introdujeron importantes trabajos de autores europeos). Por otro lado, Comunicación y Cultura, que fue fundada en Santiago de Chile, en 1973, por Héctor Schmucler, Hugo Assman y Armand Mattelart. Debido al golpe de Estado en ese país, la revista se trasladó un tiempo a Buenos Aires, entre 1974 y 1976. Se caracterizó por su denuncia al imperialismo norteamericano en torno a los 
medios, desde una perspectiva principalmente económico política.

Torrico Villanueva sintetiza en dos ejes posibles ("que se superponen") el camino por donde se desarrolló la producción intelectual latinoamericana en comunicación: por un lado "el de la tensión entre la cientificidad empirista y la teorización crítica" y por el otro el de la "predominancia fáctica de las visiones empiristas instrumentales por encima de las comprehensivas a lo largo del tiempo".

Afirma que es un campo en "pos de reconocimiento y, por tanto, sumido en una disputa"; que en su interior coexisten formas interpretativas divergentes y fuera de él compiten fuerzas antagónicas: "una que lo rechaza/minimiza por considerarlo un espacio sub-disciplinario y otra que [...] aspira tomarlo 'a su cargo' subordinando, asimismo, los conceptos comunicacionales propios a los de otros abordajes presuntamente mejor establecidos". (TORRICO VILLANUEVA, 2007:46)

De esta manera, explica que si queremos periodizar y comprender la investigación sobre comunicación en Latinoamérica necesariamente deberemos relacionarla con los procesos políticos y económicos en los que está inmersa, que la hacen posible y le dan el rumbo. Sin perder de vista, también, los movimientos que se registran en las ciencias sociales con la que mantiene un vínculo muy estrecho. (ÍBID: 47)

Torrico Villanueva propone "en términos gruesos y sólo con el propósito de proveer una guía esquemática para el análisis" que los estudios comunicacionales de los años 70 se distinguieron por "la intensa politización de izquierda" en reacción a los "cientificistas conservadores de la década precedente". (ÍBID)

En este sentido, Schmucler resume el ambiente político donde crecían las reflexiones e ideas en el Cono sur, ideas que se encarnaban en "hechos sociopolíticos con consecuencias dramáticas". La muerte del Che Guevara en 1967 y el golpe militar y muerte de Salvador Allende como "símbolo de un fracaso", "en Argentina se entretejían los hilos de una tragedia que tendría un momento destacado en marzo de 1976", con el golpe militar. "Las ideas, en alguno países de América latina, no solo se configuraban en un espacio histórico que le servía de marco, sino que eran partícipes de los acontecimientos. [... ] La teoría no pasaba a través, sino que estaba en el drama". (SCHMUCLER, 1997: 146).

A pesar de estas referencias generales, la investigación en comunicación en Argentina en la década de 1960 era aún escasa, la Escuela de periodismo y Ciencias de la información en La Plata era uno de los pocos ámbitos públicos dónde se producía. En Buenos Aires, las carreras de sociología y filosofía y letras representaban las opciones más cercanas para estos estudios.

En este sentido, Heriberto Muraro grafica esta situación -un poco jocosamente- en una entrevista realizada en 2008 para la revista Cuadernos Críticos de Comunicación y Cultura: 
“[... ] un día fui al Instituto de Sociología y, no sé por qué, pedí un par de libros de sociología de la comunicación. La bibliotecaria [... ] me dijo 'hay solo dos'. Entonces yo dije: me voy a dedicar a esto, porque leyendo dos libros soy un experto instantáneo en estos dos libros"

Otra referencia fundamental es el Instituto Di Tella y puntualmente el Centro de Investigaciones Sociales. Allí, las corrientes estructuralistas y semióticas incluían las teorías de la comunicación en sus investigaciones.

Según un trabajo de Emanuelli (1999), a mediados de 1960, en Argentina "se podían vislumbrar tres grandes líneas de estudios algunos de las cuales habían empezado a gestarse en épocas pasadas. Los estudios histórico-jurídicos (académicos tradicionales), los sondeos de opinión y audiencia (comerciales) y los estudios de contenido (morfológicos)".

\section{BÚSQUEDA DE COLECCIONES}

A modo de ejemplo, podemos ver -en el catálogo de la biblioteca de la Facultad de Ciencias Sociales de la UBA- cómo ediciones en diferentes colecciones muestran a una primera vista los distintos espacios en que se discutían los temas relativos a la comunicación. Aparecen también libros que no registran pertenencia a ninguna colección. En esta muestra, algunas fechas son aproximadas, ya que no todos los libros poseen los daos completos.

De Editorial Paidós encontramos de 1963, Comunicación de masas: una perspectiva sociológica, de Charles R. Wright, como ejemplar número 63 de la colección Biblioteca del hombre contemporáneo. De 1965, Comunicación: la matriz social de la psiquiatría, de Jürgen Ruesch y Gregory Bateson; en la colección Biblioteca de psiquiatría, psicopatología y psicosomática. Serie mayor, $\mathrm{n}^{\circ}$. 30.

Bajo la colección Biblioteca de psicología social y sociología, de 1969, con el $n^{\circ}$ 41: Los nervios del gobierno: modelos de comunicación y control políticos, de Karl W. Deutsch; y Política y comunicación, de Richard R. Fagen, en la misma colección pero en la Serie menor y con el número 18. Compartiendo esta colección, pero en la Serie mayor $n^{\circ} 52$, Sociología de los medios masivos de comunicación, de Denis McQuail, en este caso de 1972.

De este mismo año, Teorías de la comunicación masiva, como $n^{\circ} 57$ de la colección Mundo moderno (2da edición).

De Editorial Troquel encontramos, de 1968 Problemas y perspectivas de la comunicación de masas, de Dan Lacy; de 1969 Evolución política y comunicación de masas, una compilación de Lucian W. Pye. De 1973, Responsabilidad y comunicación de masas de William L. Rivers y Wilbur, Schramm y Teoría de la comunicación humana: ensayos originales, compilado por, Frank E. X. Dance, en este caso bajo la colección titulada El tema del hombre. Y de 1975 encontramos El nuevo periodismo: la prensa underground, los artistas de la no ficción y los cam- 
bios en los medios de comunicación del sistema, de Michel L. Johnson.

Luego, de la Editorial Jorge Álvarez, Conducta, estructura y comunicación, 1968, de Eliseo Verón. De la Editorial El Ateneo y bajo la colección Nuevas orientaciones de la educación, medios auxiliares de la enseñanza, El proceso de la comunicación: introducción a la teoría y a la práctica de David K. Berlo, 1969.

Del Instituto Torcuato Di Tella, encontramos Comunicación y neurosis de Eliseo Verón y Carlos E. Sluzki, de 1970 y bajo la colección Serie Naranja. Sociología.

De Ediciones Paulinas, Los medios de comunicación social, con fecha 1971, y con autor institucional: Iglesia católica. Concilio Ecuménico Vaticano [2do. 1962-1965], aparece en la colección El Pastor nos guía.

De la editorial Siglo XXI, la $5^{\text {a }}$ edición de Para leer al Pato Donald de Ariel Dorfman y Armand Mattelart con prólogo de Héctor Schmucler; año 1973 y en la colección Comunicación de masa.

De Editorial Amorrortu, Lenguaje y comunicación de George A. Miller en la colección Biblioteca de psicología, de 1974.

Y de este mismo año la $3^{\text {a }}$ edición de Teoría de la comunicación humana: interacciones, patologías y paradojas de Paul Watzlawick, Janet Helmick Beavin y Don D. Jackson, en la colección Ciencias sociales de la Editorial Tiempo Contemporáneo.

De esta búsqueda podemos ver que la única colección referida específicamente a comunicación es Comunicación de masa de Siglo XXI, el resto recoge temas de comunicación para colecciones de psicología, ciencias sociales, educación, semiótica, etcétera.

Teniendo en cuenta lo anterior, decidimos comenzar nuestra búsqueda con la colección de Siglo XXI ya que de la oferta de publicaciones sobre el tema era la única que en principio respondía a la especificidad que pretendíamos². Para eso es necesario comentar brevemente los inicios de esa casa editorial en Argentina.

\section{SIGLO XXI EDITORES Y SIGLO XXI ARGENTINA EDITORES}

El editor, químico y académico, nacido en la ciudad de la plata en 1897, Arnaldo Orfila Reynal, fue director entre 1945 y 1947 de la primera filial de Fon2A partir de 1970, la Editorial Tiempo Contemporáneo publica en Biblioteca de Ciencias Sociales la Colección Comunicaciones, bajo acuerdo exclusivo con Editions du Seuil de París, editores de la revista Communications. La supervisión general de la edición castellana está a cargo de Eliseo Verón. Los números que incluye son (La semiología, Barthes, Bremond y otros; Lo verosímil, Metz, Genette y otros; Análisis estructural del relato, Barthes, Greimas y otros; Los objetos, Moles, Baudrillard y otros y Análisis de la imágenes, Metz, Eco y otros. Esta colección será analizada en posteriores trabajos para definir la pertenencia o no de su inclusión. 
do de Cultura Económica en Buenos Aires y luego, desde 1948 a 1965 de esa misma editorial en México. En el año 1966 fundó la editorial mexicana Siglo XXI, el mismo año se abrió una filial en Argentina y un año después en España. Desde 1969 a 1976 su director fue Alberto Díaz.

Los libros publicados por esta editorial entre 1966 y 1976 fueron fuente de consulta de intelectuales y militantes de izquierda que citaban y discutían sobre sus publicaciones: El diario de Che, Las venas abiertas de América Latina, Pedagogía del oprimido o Para leer al Pato Donald. (dgLibro, 2001: 16)

Fue pionera en la publicación en Argentina y América Latina de los pensadores europeos de la izquierda francesa y los filósofos políticos italianos; entre sus editores, en la década que nos convoca, se encontraban el sociólogo Juan Carlos Portantiero y José Aricó quienes fueron los primeros en traducir y publicar los escritos de Antonio Gramsci. (LaRed21: 07/003/2011)

Siglo Veintiuno Editores en Argentina publicó 700 títulos entre agosto de 1966 y agosto de 1976, momento en el cual la casa matriz decidió cerrar la filial argentina que "ya había sido clausurada y allanada por la dictadura: colaboradores del sello habían desaparecido y varios de sus integrantes habían sido encarcelados o forzados a dejar el país". Díaz estuvo alrededor de 45 días detenido, al salir partió al exilio con la tarea de abrir una filial del sello en Colombia". (dgLibro, 2001: 16)

La editorial mexicana reabrió sus puertas en Argentina en el año 2000, Carlos Díaz (hijo de Alberto) asumió la dirección y actualmente ejerce ese cargo. Consultado para este trabajo respecto de catálogos o ejemplares de aquella época, respondió "en Siglo XXI no tenemos nada de nada. La editorial se cerró a las apuradas en 1976 y no quedó nada de material en nuestras manos" (mail de Carlos Díaz, 15 de noviembre de 2011). La búsqueda de ejemplares, puntualmente de la colección Comunicación de masa, debió comenzarse a partir de bibliotecas, librerías de viejo y anuncios o comentarios en las revistas de la época.

En el $N^{\circ} 9$ de julio de 1970, la revista Los libros publica, como hacía a menudo, una página publicitaria sobre las novedades de la editorial. Bajo el título Cuatro años, doscientos títulos realiza una especie de balance de sus cuatro años de existencia: "El libro latinoamericano sólo es concebible en una perspectiva de afianzamiento del desarrollo cultural del continente, de descubrimiento de las instancias centrales de su realidad, de promoción de la imaginación en todas las esferas de actividad humana. En este sentido la 1abor cumplida en cuatro años por Siglo XXI ha puesto en acción un mecanismo editorial preocupado por introducir con rigor y coherencia las corrientes y disciplinas que preocupan al mundo intelectual, junto a la expresión más avanzada de la creación latinoamericana".

El artículo se refiere, a su vez, a los doscientos títulos publicados en catorce colecciones y comenta brevemente el sentido de cada colección. "La serie Filosofía, Teoría y Crítica incluyó en este período obras que produjeron en 
nuestros días un decisivo impacto en el mundo europeo. Otra serie, Ciencia y Técnica, que se ocupa centralmente de la publicación de obras cuyo idioma original no es de corriente utilización en nuestros medios universitarios, contribuye a la apertura de perspectivas no frecuentadas en diferentes campos de la investigación".

Luego, hace referencia a otras series ${ }^{3}$ como Psicología y Educación, Sociología y Política, Economía y Demografía, Lingüística y Arquitectura, Historia y Arqueología y Cine y Teatro cuyas intenciones tenían que ver con la difusión de "la labor original de hombres o grupos cuya significación se juzga importante en cada una de las áreas implicadas. [... ] en estas series, más de un tercio de los libros publicados son autores latinoamericanos, hecho que constituye no solo un índice del proceso de interiorización de nuevas metodologías y formas de análisis entre los investigadores latinoamericanos, sino también una muestra del proceso de penetración en el conocimiento concreto de las realidades sociopolíticas y culturales del continente".

Esta suerte de declaración de intensiones de la editorial demuestra de alguna manera que desde sus inicios tuvo un perfil de izquierda "no partidaria" y un fuerte compromiso con los valores latinoamericanos. De esta manera, en poco tiempo se convirtió en una referencia insoslayable para las ciencias sociales.

Por otro lado podemos ver la importancia dada a las colecciones "doscientos libros en catorce colecciones" y las declaraciones y características específicas de cada serie. En principio, se podría decir que en esos primeros cuatro años de existencia de la editorial no han salido números aislados y las colecciones fueron pensadas y planificadas, la mayoría coinciden con disciplinas de las ciencias sociales, pero están agrupadas de a pares (Psicología y Educación, Cine y Teatro). Claramente el público al que se dirige la editorial está conformado por intelectuales, académicos y militantes.

A partir de 1971, la editorial comienza a llamarse Siglo XXI Argentina Editores S.A. Los anuncios publicitarios de la revista los libros aparecen con algunos cambios, mantiene un eslogan de años anteriores (Signos para un mundo que se piensa) pero agrega la siguiente leyenda: Una editorial para acompañar activamente el proceso transformador de América Latina. Una editorial para difundir las investigaciones más rigurosas sobre la actividad continental y las teorías avanzadas del pensamiento contemporáneo. Una editorial que, al coor3 El glosario de términos del Centro Regional para el Fomento del Libro en América Latina, el Caribe, España y Portugal (CERLALC) define el término colección como: "Conjunto de obras independientes (con numeración o sin ella) cuya relación, que puede ser temática, con más frecuencia se limita a igualdad de características y a un título colectivo que se repite en cada una de ellas además del suyo propio. La colección es un conjunto de varios títulos que pueden ser de diversos autores y que pueden editarse sin orden y espacios de tiempos distintos [...] una colección puede estar compuesta además por series. Cada libro puede o no tener un número." Al término serie lo define como: "[... ] una subdivisión dentro de una colección”. En el artículo mencionado los dos términos son usados como sinónimos. 
dinar su labor con México y España, constituirá un puente entre los pueblos de habla española. Pareciera abrirse a partir de esta fecha una nueva etapa que se podría pensar más independiente de la casa matriz mexicana.

El N$^{\circ} 31$ de la revista Los libros, de agosto-septiembre de 1973 publica el aviso habitual de una página de esta editorial bajo el título Los dos primeros años de Siglo XXI Argentina Editores y en el pie de página un eslogan que dice Tres empresas unidas en el proyecto editorial más significativo de nuestra lengua, haciendo referencia a la editorial de México, Argentina y España. En esa página presenta "algunos" de los 119 títulos nuevos y 51 reediciones y enumera otros tantos títulos con sus respectivas colecciones: en este caso Teoría, Sociología y política, Creación literaria, Historia, Crítica literaria, Economía, Educación, Lingüística, Pensamiento fundamental, Psicología, Arquitectura y Urbanismo, El hombre y sus obras, Humor, Comunicación de masa.

Vemos que algunas colecciones se mantienen de la etapa anterior, otras cambiaron, se desdoblaron y se agregaron nuevas. El sintético recorrido anterior acerca de los orígenes de la editorial y sus cambios y algunas características de sus colecciones son el marco previo y contemporáneo a la aparición de la colección Comunicación de masa4.

\section{LA COLECCIÓN COMUNICACIÓN DE MASA}

El número 33 de la revista Los libros, de enero y febrero de 1974, publica la habitual hoja publicitaria de Siglo XXI, pero en este caso, solo se refiere a la colección Comunicación de masa. Es una página en la cual el nombre de la colección está en letras de molde y ocupa casi un cuarto de la página, luego podemos ver que cuenta con ocho publicaciones, aparece el título del libro, el autor y una breve reseña de cada uno, que según constatamos, es un fragmento de la contratapa de cada edición.

De esos ocho títulos, al menos siete fueron publicados entre 1972 y 1973.

En junio de 1972 se publica Para leer al pato Donald. Comunicación de masa y colonialismo, de Ariel Dorfman y Armand Mattelart y con ese ejemplar -publicado ese mismo año previamente por Ediciones Universitarias de Valparaíso, en Chile- se inicia la colección. (a finales de 1973 se publicaba la $7^{\circ}$ edición).

La semiología, de Pierre Guiraud, Primera edición: antes de septiembre de 1972, tirada: s/d; Tapa: s/d; tamaño: 18 x 11 cm.; tipo de encuadernación: rústico; cantidad de páginas: 134 . Se publico en la colección Lingüística, luego en

4En principio, pensamos que esta colección fue la primera en Argentina referida específicamente a temas de comunicación, pero un estudio más profundo de las editoriales Tiempo Contemporáneo, Nueva Visión, Jorge Álvarez, Troquel, Amorrortu, entre otras, nos dirá si efectivamente los títulos sobre la temática que publicaron antes y durante el periodo de esta colección eran obras independeintes, pertenecían a otras series o bien existían colecciones similares y aun no las hemos registrado (ver nota al pie 2 ). 
la revista Los libros que comentamos al inicio de este apartado, Siglo XXI lo incluye como perteneciente a la colección Comunicación de masa.

Cine, Cultura y Descolonización, de Fernando Solanas y Octavio Getino. Primera edición: 1972 o 1973, tirada: s/d; Tapa: s/d; tamaño: 20 x 14 cm.; tipo de encuadernación: rústico; cantidad de páginas: 204.

El lenguaje de la publicidad de Luisa Block de Behar. Primera edición: julio de 1973, tirada s/d; Tapa: Isabel Carballo; tamaño: 20 x 14 cm.; tipo de encuadernación: rústico; cantidad de páginas: 218.

La información de clase, de Vladimir Ilich Lenin, traducción de Augusto Bianco (introducción) y Marisa Cortazzo (textos). Primera edición: octubre-noviembre de 1973, tirada de 3000 ejemplares; Tapa: Isabel Carballo; tamaño: 20 X 14 cm.; tipo de encuadernación: rústico; cantidad de páginas: 252. La primera edición en italiano se publicó en 1972 por Guaraldi Editor, Rimini (L'informazione di clase).

La comunicación masiva en el proceso de liberación, de Armand Mattelart. Primera edición: noviembre de 1973, tirada: s/d; Tapa: Isabel Carballo; tamaño: 20 x 14 cm.; tipo de encuadernación: rústico; cantidad de páginas: 263.

Agresión desde el espacio. Cultura y napalm en la era de los satélites, de Armand Mattelart. Segunda edición: fines de 1973; tirada: s/d; Tapa: s/d; tamaño: 20 x 14 cm.; tipo de encuadernación: rústico; cantidad de páginas: 199.

El cine como propaganda política, de Alexander Medvedkin. Primera edición: finales de 1973; tirada: s/d; Tapa: s/d; tamaño: 20x14; tipo de encuadernación: rústico; cantidad de páginas: 112.

Todos tienen tipo de encuadernación rústica y tamaño 20x4; salvo La semiología, que tiene otras medidas y esto corrobora de alguna manera que perteneció a otra colección y nos quedaría averiguar a qué responde la decisión de ese cambio. Se podría, en principio, especular con decisiones académicas, económicas o simplemente por cuestiones operativas de la editorial. Como dijimos, incorporar una obra dentro de una colección suele ser una estrategia que puede darle una nueva identidad a un volumen a destinarlo, por ejemplo, a un público diferente.

Todas son ediciones cuidadas, con diseño de tapas y buena encuadernación y se mantienen en buen estado a pesar de los años.

El único dato que indica que es una colección lo da el hecho de que en la primera hoja en blanco en la parte superior aparece la leyenda Comunicación de masa. Pero además de eso no hay ningún otro indicio; si bien tienen un diseño similar cuatro de los ocho volúmenes, los otros cuatro no responden al mismo diseño. Las contratapas son fragmentos literales de los prólogos o introducciones de cada libro, salvo El lenguaje de la publicidad, que parece escrito especialmente como contratapa; tampoco tienen solapas o alguna hoja final donde se reproduzcan los títulos que pertenecen a la misma colección o a otras. 
En definitiva, no existen declaraciones de intenciones, comentarios ni ningún dato acerca de la colección, no existen otras marcas que no sean el ejemplar mismo, su pertenencia a la colección y la elección de su publicación. En la revista Los Libros, que ya hemos comentado, las publicidades de Siglo XXI le dan mucha importancia a las colecciones, sin comentarios o declaraciones, pero siempre aparecen los títulos incluidos dentro de ellas.

Deberíamos ir desentrañando cuánto de todo esto responde a estrategia editorial, cuánto a las condiciones concretas de producción, cuánto a cuestiones comerciales y cuánto a cuestiones académico disciplinares.

Parte de las respuestas a estas dudas pueden deducirse de los comentarios de Alberto Díaz -que como dijimos dirigió la editorial en sus inicios en Argentina-, "en Siglo XXI en esa época no había directores formales de colección. La práctica era que aportábamos a las colecciones según nuestros saberes o áreas de interés. La única colección que tenía un director definido eran los 'Cuadernos de Pasado y Presente', que dirigía José ‘Pancho' Aricó. La colección de Comunicación, la llevaba en la práctica Héctor Schmucler" (mail de Alberto Díaz, 03 de marzo de 2012).

Una primera mirada ubica la emergencia de esta colección en un momento particular tanto en lo político como en lo referente al campo de la comunicación. Como vimos, el primer número de la colección es Para leer al Pato Donald, su autor Mattelart co dirigía la revista Comunicación y Cultura con Schmucler, quien, aunque informalmente, dirigía la colección que investigamos. La influencia creciente del pensamiento de Mattelart y la situación chilena previa al golpe de Allende parecen el contexto generador de la colección. También, los debates entre la revista mencionada y la revista Lenguajes que dirigía Eliseo Verón. Por esta misma época, Verón, a su vez llevaba adelante la Colección Comunicaciones, por lo cuál quizás fuera la colección Comunicación de masa una herramienta más de esa disputa teórica.

Nos resta entonces, adentrarnos en otras colecciones y a partir de los datos que nos ofrecen pensar en el proceso de edición, el proceso de creación de nuevas colecciones -sus motivaciones, su diseño, el lugar asignado al director de colección, los programas enunciados, los catálogos, la difusión realizada, la repercusión obtenida, su perduración en el tiempo o las circunstancias de su cese- todas estas aristas pueden ayudarnos a comprender mejor ese período tan productivo en términos tanto de creaciones editoriales como de pensamiento teórico político que fueron las décadas de 1960 y 70.

\section{REFERENCIAS}

LENARDUZZI, V. (1999). Comunicación y cultura. Itinerarios, ideas y pasiones.Buenos Aires: Eudeba.

RIVERA, J. (1987). La investigación en comunicación social en Argentina. Buenos Aires: Ed 
Punto sur.

CASULLO, N. (1996). "Diálogo con los investigadores argentinos de la comunicación/cultura/medios". (p. 22.). Buenos Aires: Revista Mapa Nocturno.

Entrevista a Heriberto Muraro (2008). "La formación del campo y las prácticas profesionales. Un recorrido para la comunicación de masas y la cultura política”. En Cuadernos Críticos de Comunicación y Cultura. Sumario $N^{\circ} 4$ (pp. 13-30). Buenos Aires.

EMANUELLI, P. (1999). "Investigación de la comunicación en Argentina - Reflexiones sobre la investigación crítica”. En Ámbitos. Revista Andaluza de Comunicación, Número 2, Facultad de Ciencias de la Información, Universidad de Sevilla.

SPOLETINI, B. (1985). Comunicación e Iglesia Latinoamericana. Buenos Aires: Ediciones Paulinas.

DE SAGASTIZÁBAL, L. (1995). La edición de libros en la Argentina. Una empresa de cultura. Buenos Aires: Eudeba.

De Diego, J. (dir.) (2006). Editores y políticas editoriales en Argentina (1880-2000). Buenos Aires: FCE.

INVERNIZZI, H. y J. Gociol (2003). Un golpe a los libros. Represión a la cultura durante la última dictadura militar. ( $2^{\mathrm{a}}$ edicion). Buenos Aires: Eudeba.

Muraro, H. (comp.) (1977). Comunicación de masas. Buenos Aires: Centro editor de américa latina.

NEIBURG, F. y M. Plotkin (compiladores) (2004). Intelectuales y Expertos. La Constitución del Conocimiento Social en la Argentina. Buenos Aires: Paidós.

MÁS LIBROS PARA MÁS. Colecciones del Centro Editor de América Latina (2008). Buenos Aires: Ediciones Biblioteca Nacional, Serie Índices y Bibliografías; edición de Judith Gociol et al. SCHMUCLER, H. (1997). Memoria de la comunicación. Buenos Aires: Editorial Biblos. TORRICO VILLANUEVA, E. (2007). "Teorías y tendencias temáticas en la investigación de la Comunicación en América Latina”. En Alfonso, A. et al (Comps.). 70 años de Periodismo y Comunicación en América Latina. Memoria y perspectivas (p.45-50). La Plata: Universidad Nacional de La Plata.

Un golpe a los libros (2001). Buenos Aires: Dirección General del Libro y Promoción de la Lectura, Secretaría de Cultura de la CABA. Dirección: Manuela Fingueret. Coordinación: Judith Gociol.

"Siglo XXI cumple años y festeja publicando a Galeano" (2011). La Red21 Cultura. Uruguay, 07 de marzo. Disponible en: http://www.Ir21.com.uy/cultura/443440-siglo-xxi-cumple-anos-yfesteja-publicando-a-galeano. 


\section{Bruno De Angelis}

Docente e pesquisador da Universidad Nacional de Quilmes UNQ e atualmente integra o projeto de pesquisa "El orden de lo diverso. estudio sobre las colecciones argentinas en los años sesenta". Graduado em Comunicação Social pela UNQ. É Diretor de materiais didáticos da Universidad Virtual de Quilmes e participa em projetos de extensão relacionados com a divulgação científica. 